\title{
Long-term global climate prediction; rogue science?
}

\section{Opinion}

Climate change has been a buzzword in global development discourse for the past quarter century or slightly longer. It refers to the extremes of weather conditions experienced in different parts of the world, which would eventually lead to permanent changes in long-term weather patterns (it is believed). When excessive drought conditions have been experienced for some time in a region, climate change has readily been pointed as the course. Similarly, when high floods due to excessive rainfall are observed, the cause has been attributed to climate change. Melting of glaciers due to relatively higher temperatures has been linked to global warming which is one aspect of climate change. But curiously, when there is excessive snowfall in some countries during winter, this is also blamed on global warming. Thus one may ask; can a phenomenon that causes warming be at the same time responsible for cooling? Climate is normally defined in terms of six variables; temperature, rainfall/ precipitation, humidity, solar radiation, air pressure and wind. Air composition or quality is also increasingly considered as an element of climate. When there is erratic or excessive change in the core variables, then scientists have been quick to point at changing climate. In predicting climate, historical data is analyzed and developed into models for predicting the future. The data can be applied under the architecture of a mechanistic model that uses the underlying thermophysical processes to relate input and output. The term energy and mass balance may be used to describe such mechanistic models. Computational fluid dynamics packages based on these energy and mass balances are also being used nowadays. Alternatively, the inputoutput behavior of the system may be related without considering the underlying thermo-physical processes in the system. Such data-based models are commonly referred to as black-box models. Large sets of input-output data can easily be developed into prediction models through 'system identification' which is essentially regression models for large data sets.

Apart from using models to predict climate, there has been extensive use of satellites to monitor cloud cover and movement with the aim of predicting rainfall events and even intensities. Whereas, sometimes the predictions may be accurate, there are many instances where weather forecasters have been awfully disappointed in their predictions. This suggests that atmospheric processes are not fully predictable; there is an element of exogenous control. That is to say the climate of a region may follow a general pattern but it is never fixed. In horticultural greenhouse we have control inputs and exogenous inputs (disturbances). Control inputs are adjusted by human actions while exogenous variables play out naturally. We know that the exogenous variables are never uniform; they are varied by nature. Would it be fair to say that exogenous variables are controlled by God? Well, we also know that there are people who predict the weather by prophecy or pray for rain with positive results. In terms of sensitivity of variables, we know that solar intensity has perhaps the most important influence on weather and climate. But scientific measurements over the years have shown that there is an upper limit of solar radiation on the earth's

\author{
Volume 5 Issue 3 - 2021
}

\author{
Patrick Ajwang \\ Department of Agricultural and Biosystems Engineering, Jomo \\ Kenyatta University of Agriculture and Technology, Kenya
}

Correspondence: Patrick Ajwang, Department of Agricultural and Biosystems Engineering, Jomo Kenyatta University Of Agriculture And Technology, College of Engineering and Technology, Juja Campus, P.O Box 62000 - 00200 Nairobi, Kenya, Email ajwang@agr.jkuat.ac.ke

Received: May 10, 2021 | Published: May 17, 2021

surface, called a solar constant. And the amount of solar radiation varies according to the season of the year, time of the day, cloud cover and solar azimuth. Excessive solar radiation has hardly been pointed out as the cause of climate change. But gaseous emissions into the atmosphere are blamed for blanketing the earth, preventing the movement of long-wave radiation from the earth back into the sky. Human settlement, deforestation, animal production and agricultural activities are also thought to interfere with climate, especially through their effects on the water cycle and atmospheric thermal balance. This has led to the notion that climate change is a man-made phenomenon.

In thermodynamics the earth cannot be accurately described as a closed system. It can also not be called an isolated system because there are interactions between it and other elements of the universe. In fact, the earth is an open system which is part and parcel of the universe that is an infinite system; its scale and complexity is unfathomable. It is therefore simplistic to say that gaseous emissions accumulate in the atmosphere to impede the escape of radiation thus causing global warming. So is long-term global climate prediction a con game? Is it a case of rogue science? Well, honest meteorologist will tell you that their weather prediction models have an accuracy of less than $80 \%$ over a one week horizon. Many are also the occasions where hurricanes or tornadoes changed their paths without warning. Dark cloud covers may also disappear from the skies without depositing any rains. Sometimes we might get the weather prediction right, but many times we have been wrong. In one of the wisdom books in the Bible it is recorded that the sower who always monitors the movement of the clouds will never reap anything. In our desire for a sustainable development in this world we need to temper science with faith. Good science confirms the Bible. God cares.

\section{Acknowledgments}

None.

\section{Conflicts of interest}

The author declares that there is no conflict of interest. 